\title{
Factors Associated with Condom Use Self-Efficacy Among Preparatory School Students in Sodo Town, Southern Ethiopia 2020: A Cross-Sectional Study
}

This article was published in the following Dove Press journal:

HIVIAIDS - Research and Palliative Care

\section{Natnael Atnafu Gebeyehu' Kebreab Paulos Chanko (D) Yibeltal Mesfin Yesigat iD ${ }^{2}$ \\ 'Department of Midwifery, College of Health Science and Medicine, Wolaita Sodo University, Wolaita Sodo, Ethiopia; ${ }^{2}$ Department of Midwifery, College of Health Science and Medicine, Woliktie University, Wolkitie, Ethiopia}

Background: Condoms are playing a central role in the prevention of sexually transmitted infections, human immune virus, and unintended pregnancy particularly among young peoples. Therefore, this study aimed to assess factors associated with condom use selfefficacy among preparatory school youths in Sodo town, Ethiopia.

Methods: This institution-based cross-sectional study was conducted among 424 study participants from January 25 to February 20, 2020. Data were collected using a validated pretested structured questionnaire. Descriptive analysis was done and results were presented in texts and tables. Those variables at bivariate analysis with p-value $<0.2$ at $95 \%$ confidence level were moved to a multivariate logistic regression model to control potential confounding variables. Odds ratio with $95 \%$ confidence interval was computed to ascertain association during multivariate analysis model. Statistical tests at P-value $<0.05$ were considered as cutoff point to determine statistical significance.

Results: Out of a total of 424 youths, only 416 had participated in the study yielding a response rate of $98.1 \%$. The prevalence of higher self-efficacy among respondents was $70 \%$. Factors that were independently associated with condom use self-efficacy in multivariate analysis were having sexual experience ( $\mathrm{AOR}=2.047,95 \% \mathrm{CI}: 1.141-3.675$ ), having life goals ( $\mathrm{AOR}=1.736$, 95\% CI: 1.021-2.951), having social support ( $\mathrm{AOR}=2.395,95 \% \mathrm{CI}: 1.501-5.458)$, and having good knowledge about condoms (AOR=2.535,95\% CI:1.499-4.282).

Conclusion: The finding of this study showed that participants who had sexual experience, social support, knowledge of the human immune virus, and having life goals were found to be significantly associated with condom use self-efficacy. These results suggest ways to increase self-efficacy for condom use among youth that can increase the effectiveness of future interventions for youth.

Keywords: condom use, condom use self-efficacy, youth, Sodo Town

\section{Introduction}

Condoms have played a crucial role in the prevention of sexually transmissible infections (STIs) and HIV/AIDS over the past decade. The transmission of STIs including HIV/AIDS can be prevented by almost $100 \%$ through correct and consistent condom use. ${ }^{1}$ However, evidence shows inconsistent condom use among young people, which can be related with behavioral, personal and cultural reasons, is one of the major risk factors in the expansion of the HIV epidemic. ${ }^{2}$ 
This study focused on adolescents and young adults since, having survived childhood disease while not yet experiencing health conditions that are faced in later adulthood, they are in the highest stage of life. ${ }^{3,4}$ However, AIDS-related mortality among youth has been increasing in recent years, even while a decrease in all other age groups has been observed. ${ }^{5}$ This is due to the prevalence of HIV among youth in sub-Saharan Africa, which constitutes up to $85 \%$ of global HIV infections. ${ }^{6}$ In Ethiopia, a report found that 87,000 young people are living with HIV, with only 8700 new infections among young people living across the country. ${ }^{7}$

A high proportion $(60 \%)$ of unsafe abortion in Africa occurs among women under the age of 25 years. ${ }^{8}$ In Ethiopia, unwanted pregnancy among youth and adolescents is a major sexual and reproductive health challenge. Fiftyfour percent of women under age 15 and $37 \%$ of youth aged 20-24years have an unwanted pregnancy. ${ }^{9}$ Furthermore, unprotected sexual intercourse is the main route of HIV transmission among young people in Ethiopia, as they are the most likely to engage in high risk sexual behavior. ${ }^{10}$ The sustainable development goals of several initiatives, including the World Health Organization (WHO), United Nations Aid for International Development (UNAIDS), United Nations Population Fund (UNFPA), ${ }^{11}$ have focused on promoting condom negotiation strategies including increasing self-efficacy regarding condom use as a means to improve safe sexual behavior and reducing the risk of HIV, STIs, and unwanted pregnancy. ${ }^{5}$ Though, consistent condoms use plays a central role in the prevention of HIV transmission, ${ }^{12,13}$ utilization among young people requires exercising control on their condom use behavior.

Literature reported that self-efficacy is one of the most significant predictors of condom use. ${ }^{14-18}$ According to social cognitive theory, self-efficacy is a central concept in which both outcome and efficacy of expectations are critical in the promotion of health and behavioral change. ${ }^{19}$ Bandura $^{20}$ defines the term "self-efficacy" as a "judgment of one's capability to accomplish a certain level of performance". The social cognitive theory posits that there is a dynamic interaction between environmental factors, personal factors, and human action. ${ }^{21}$ Condom efficacy is defined as a person's confidence in his or her ability to effectively use a condom during sexual intercourse. ${ }^{22}$ People with a high sense of condom use self-efficacy are more likely to use condoms than those who have doubts. ${ }^{23}$ Hence, increasing self-efficacy is recommended for improving condom use among young adults. ${ }^{16,23,24}$
Several studies showed that self-efficacy for protective behaviors among youth is associated with effective condom use. ${ }^{25-28}$ A study done in America found that higher self-efficacy for condom use was significantly associated with people who were younger, had higher self-esteem, and communicated better with their sexual partner. ${ }^{29}$ For young women in South Africa, not using condoms during their first sexual encounter, having a history of unwanted sex, and believing that condom use implies distrust in one's partner were significantly associated with low selfefficacy whereas understanding how to avoid HIV, speaking with a guardian about HIV/AIDS, and having life goals were factors associated with high self-efficacy. ${ }^{30}$ Another study in Mozambique showed that demographic variables such as age, education level, and marital status were associated with condom use self-efficacy among women at risk of contracting HIV/AIDS. ${ }^{31}$

In Ethiopia, utilization of condoms among youth is limited even when condoms are available and there is knowledge about their effectiveness in preventing $\mathrm{HIV}^{32,33}$ Consistent condom usage is very low (20\%) among secondary school and college students. ${ }^{33}$ To the best of the researcher's knowledge, a study of the factors associated with condom use self-efficacy among preparatory school students in Ethiopia in general and in the study area in particular, has not been conducted. Therefore, this study amid to assess factors associated with self-efficacy on condom use among preparatory school students in Sodo town, Southern Ethiopia.

\section{Methods}

\section{Study Area, Design, and Participation}

Cross-sectional study design was conducted in Sodo Town, Southern Ethiopia from January 25 to February 20, 2020. The town is located $320 \mathrm{Km}$ far from the capital city of Addis Ababa. The total population of the town in 2018, received from the town administrative office, was 132,271 (62,340 males and 69,931 females) from these, 3263 were youth people (15-24 years). ${ }^{34}$ The town has four preparatory schools of which one is governmental. The preparatory school enrolls grade 11 and 12 and were attended a preuniversity education. All preparatory school students who attended their education in all schools of Sodo town were considered as a source of the population whereas all preparatory school students attended education in Sodo town during the study period were the study population. Those students who attended their education during the study period, and selected with the sampling procedure were study 
units. All volunteer preparatory school students who were available during the study period were included in the study. However, all preparatory school students who were mentally and physically seriously ill during the study were excluded from the study.

\section{Sample Size Determination and Procedures}

The sample size was determined by using a single population proportion formula by considering the following assumptions: $50 \%$ of condom use self-efficacy to gain a maximum sample size for the study, 95\% confidence level, 5\% marginal error, and 10\% non-response rate. Based on these, a total of 424 youth were taken as a final sample size. After preparing a sampling frame, a systematic random sampling technique was applied to select the study participants. The sampling interval (k-value) was calculated by dividing the total youth population available in all preparatory schools (1898) into the calculated sample size, giving approximately $(\mathrm{K}=5)$. After selecting the first study participant by using a lottery method, we used systematic sampling technique to recruit every $\mathrm{K}^{\text {th }}$ eligible respondents $\left(\mathrm{K}=5^{\text {th }}\right)$ from the list of the sampling frame until the total sample size reached.

\section{Measures}

\section{Measures of Condom Use Frequency}

It was measured by asking the respondents "how often did you use condoms with your last sexual partner?". Response options were "always", "sometimes" and "never". Based on the distribution of responses, we dichotomized those who responded "always" versus all others.

\section{Measures of Condom Use}

It was measured by asking "The last time you had sex with your most recent sexual partner, did you use a condom?" Response options were "Yes" or "No."

\section{Consistent Condom Use}

It was measured by asking "Did you use a condom at every sexual intercourse?" Response options were "Yes" or "No".

\section{Measures of Knowledge of Condoms}

Knowledge index was built from the answers to 18 questions on a condom with Yes/No answers. Based on the answers to these knowledge questions, the index was classified as good knowledge (score 10-18) and poor knowledge (score $\leq 9$ ).

\section{Measures of Attitude on Condom Use}

It was measured by using seven Likert-scale items (strongly disagree to strongly agree) with a score range of 1 to 4 where the higher score represents a negative attitude and lower scores revealed a positive attitude.

\section{Measures of Condom Use Self-Efficacy}

It was measured by using nine validated items. Answers were given in a five-point Likert-scale format: Strongly agree (4), agree (3), neutral (2), disagree (1), strongly disagree (0). In the present study, the Cronbach's alpha value was 0.821 . The mean was calculated with a possible high score of 4 and a possible low score of 0 . Higher mean scores (3 and 4 ) indicated higher self-reported strength of condom use self-efficacy whereas lower scores (0-2) indicated lower self-efficacy of condom use.

\section{Social Support}

It was measured by asking "If I were sick I could easily find someone to help me with my daily activities. The response contains: Yes/no

\section{Data Collection Tool, Quality, and Procedures}

A pretested structured self-administered questionnaire was used to collect the data by using every fifth interval of students from the sampling frame. The tool was prepared first in English and translated to the local language (Woliatagna), and then translated back to the English language to keep internal consistency. The tool was adapted from validated previous studies and customized with local situations. $^{35-39}$ The questioner contains socio-demographic characters, knowledge of condom, attitude towards condom usage, and condom use self-efficacy related questions were used to conduct the research. Four data collectors and one supervisor were recruited and trained about procedures of data collection and research ethics for one day. The tool was checked for content validity by a panel of experts provided $90.8 \%$ of the content validity index and also checked for the reliability of the instrument with a score of $0.924 \%$. A pretest was conducted on 22 preparatory school students in Hosanna Town. Data were checked for completeness and consistency by the supervisors and principal investigator.

\section{Data Processing and Analysis}

The data were cleaned and entered using Epi-data manager version 4.2 and exported to SPSS version 24 for statistical analysis. Descriptive statics were done and presented in the 
form of tables and texts. The goodness of fit model was checked by using Hosmer Lemeshow test which was found to be greater than the significance level $(\mathrm{P}$-value $=0.05)$ was accepted and the final model was checked for the multicollinearity test by using tolerance and Variance Inflation Factor Bivariate and multivariate models were used to assess the presence of any association between each independent variable and the dependent variable. Crud and adjusted odds ratios were used to know and ascertain any association between the independent and dependent variables while significance was declared using a 95\% Confidence interval. Those candidate variables at Bivariate logistic regression with a $p$-value $<0.2$ were moved to the Multivariate logistic regression model for the dependent variables to control potential confounding variables. Those variables with $\mathrm{P}$-value $<0.05$ at multivariate analysis were considered as statically significant to condom use self-efficacy in this study.

\section{Results}

\section{Socio-Demographic Characteristics of} Participants

Out of a total of 424 respondents, 416 respondents had participated in providing a response rate of $98.1 \%$. Of these more than half of the study participants, 258 (62\%) were found under the age of 20-24 years, and the remaining 158 (38\%) were categorized under the age of 15-24 years. The mean age of the study participants was 20.24 with \pm SD 2.78 . With regards to ethnicity, the majority of study participants $261(62.7 \%)$ were Wolaita, and half of the participants, 217 $(52 \%)$ were protestant by religion. Three hundred sixty (76\%) of the participants had a rating on religious importance. Concerning marital status, the majority of respondents $194(46.6 \%)$ had no sexual partner during the time of study.

Among the study participants, the majority of the 261 $(62.7 \%)$ had life goals whereas the remaining had not. Of the respondents, the majority of the $326(78.4)$ had a previous history of condom use and $336(80.8 \%)$ of the participants had sexual experience. Three hundred thirty-four $(80.3 \%)$ of the respondents had a history of unintended sex, and 348 $(83 \%)$ of the study subjects had social support (See Table 1).

\section{Factors Associated with Self-Efficacy on Condom Use Among Study Participants}

On bivariate analysis participants who had life goals, sexual experience, rating on religious importance, history of previous condom use, exposure to condom advertising, history of
Table I Socio-Demographic Characteristics of Preparatory School Students in Sodo Town, Southern Ethiopia $2020(n=4 \mid 6)$

\begin{tabular}{|c|c|c|}
\hline Variables & Frequency & Percent \\
\hline \multicolumn{3}{|l|}{ Sex } \\
\hline Male & 218 & 52 \\
\hline Female & 198 & 46 \\
\hline \multicolumn{3}{|l|}{ Age } \\
\hline $15-19$ & 158 & 38 \\
\hline $20-24$ & 258 & 62 \\
\hline \multicolumn{3}{|l|}{ Marital status } \\
\hline Married & 84 & 20.2 \\
\hline Living together & 138 & 33.2 \\
\hline Other & 194 & 46.6 \\
\hline \multicolumn{3}{|l|}{ Religion } \\
\hline Protestant & 217 & 52 \\
\hline Orthodox & 98 & 24 \\
\hline Catholic & 54 & 13 \\
\hline Muslim & 47 & 11 \\
\hline \multicolumn{3}{|l|}{ Ethnicity } \\
\hline Wolaita & 261 & 62.7 \\
\hline Gurage & 103 & 24.8 \\
\hline Other $^{b}$ & 52 & 12.5 \\
\hline \multicolumn{3}{|l|}{ Talk about sex with mother } \\
\hline Yes & 175 & 42.1 \\
\hline No & 241 & 57.9 \\
\hline \multicolumn{3}{|l|}{ Talk about sex with father } \\
\hline Yes & 158 & 38 \\
\hline No & 258 & 62 \\
\hline \multicolumn{3}{|l|}{ Alcohol drink } \\
\hline Yes & 133 & 32 \\
\hline No & 283 & 68 \\
\hline \multicolumn{3}{|l|}{ Smoke } \\
\hline Yes & 91 & 21.9 \\
\hline No & 325 & 78.1 \\
\hline \multicolumn{3}{|l|}{ Drug } \\
\hline Yes & 138 & 33.2 \\
\hline No & 278 & 66.8 \\
\hline \multicolumn{3}{|l|}{ History of previous condom use } \\
\hline Yes & 326 & 78.4 \\
\hline No & 90 & 21.6 \\
\hline \multicolumn{3}{|l|}{ Having life goals } \\
\hline Yes & 261 & 62.7 \\
\hline No & 155 & 37.3 \\
\hline \multicolumn{3}{|l|}{ Sexual experience } \\
\hline Yes & 316 & 80.8 \\
\hline No & 100 & 19.2 \\
\hline
\end{tabular}

(Continued) 
Table I (Continued).

\begin{tabular}{|l|l|l|}
\hline Variables & Frequency & Percent \\
\hline $\begin{array}{l}\text { History of unintended sex } \\
\text { Yes }\end{array}$ & 334 & \\
No & 82 & 80.3 \\
\hline Rating religious importance & & 19.7 \\
Yes & 316 & \\
No & 100 & 76 \\
\hline Social support & & 24 \\
Yes & 348 & \\
No & 68 & 84 \\
\hline Knowledge of condoms & & 16 \\
Knowledgeable & 182 & 43.8 \\
Not knowledgeable & 234 & 56.2 \\
\hline Attitude & & \\
Positive attitude & 132 & 31.7 \\
Negative & 284 & 68.3 \\
\hline
\end{tabular}

Notes: ${ }^{a} \mathrm{Had}$ no sexual partner at the time of data collection. ${ }^{\mathrm{b}} \mathrm{Hadiya}$.

unintended sex, social support and having good knowledge towards condom use were factors showed statically significant association with self-efficacy of condom use among study participants. On multivariate analysis, participants who had social support, rating of religious importance, having life goals, and good knowledge on condom use were found to be statically significant with self-efficacy on condom use. Participants who had life goals were 2.3 times more likely to have self-efficacy on condom use than their counterparts (AOR $=2.305,95 \%$ CI: 1.021-2.951). Respondents who had social support were 2 times more likely to have self-efficacy than those who had no social support (AOR $=2.265,95 \%$ CI:1.501-5.458). Study participants who were previous sexual experience were 3 times more likely to have self-efficacy than their counterparts (AOR=3.072,95\% CI:1.141-3.675). Those respondents who had good knowledge were 2 times more likely to have self-efficacy than those who had poor knowledge of condom use (AOR=2.242,95\% CI:1.499-4.282). Participants who had exposure to condom advertising were 3.8 times more likely to have condom use self-efficacy than their counterparts (AOR=3.832, 95\% CI: $1.120-3.041)$. The respondents who had a history of unintended sex were 2.8 times more likely to have condom use self-efficacy than those who did not have a history of unintended sex (AOR $=2.787,95 \mathrm{CI}: 2.492-6.827)$. Study subjects rating as the importance of religious were 2 times more likely to have condom use self-efficacy than their counterparts $(\mathrm{AOR}=$ 2.242,95\% CI:2.082-6.002) (See Table 2).

\section{Discussion}

The current study was intended to assess the factors associated with condom use self-efficacy among preparatory school students in Sodo, Ethiopia. As a result, this study contributes to identifying and understanding the issues involved in maintaining the sexual and reproductive health of youths in sub-Saharan Africa.

A significant proportion of the study participants had more than one sexual partner, and only $22 \%$ reported that consistent condom use. This finding was lower than studies conducted in Ethiopia $(55.8 \%, 56.7 \%$, and $78.9 \%),{ }^{40-42}$ Nigeria (38.6\%), ${ }^{43}$ and China $(82.4 \%) .{ }^{44}$ This discrepancy might be explained by the presence of socio-demographic variations across the population, the availability and accessibility of condoms, the implementation of sexual and reproductive policy, and the quality of the health system infrastructure. Moreover, there were differences in the study populations. The former study was conducted among individuals who were HIV/AIDS positive and had already received antiretroviral therapy. These individuals had the chance to receive counseling about condoms during their follow up, which contributed to more regular condom use. To the best of the researchers' knowledge, there were no findings smaller than the current study so as not to discuss on that manner.

In the current study, multivariate analysis showed that knowledge about condoms was significantly associated with condom use self-efficacy, which was in agreement with findings from South Africa. ${ }^{30}$ This positive association is important because, although many studies have found that knowledge alone is not enough to cause immediate behavioral change, it may do so in the long term. ${ }^{45-47}$ Knowledge about the efficacy of condoms to prevent STIs and HIV/AIDS may lead an individual to properly use condoms in every instance of sexual contact thereby minimizing risk.

Participants in this study who had social support were more likely to have self-efficacy to use condoms than their counterparts, which was in line with studies done in Mexico $^{48}$ and Bangladesh. ${ }^{49}$ Conversely, these studies showed that participants who experienced a lack of social support were more efficacious to use condoms and that a low level of social support was associated with sexual risk taking. ${ }^{50,51}$ A possible strategy for maximizing selfefficacy for condom use would be to take a social-cognitive 
Table 2 Bivariate and Multivariate Analysis of Factors Associated with Self-Efficacy on Condom Use Among Preparatory School Students in Sodo Town, Southern Ethiopia $2020(n=416)$

\begin{tabular}{|c|c|c|c|c|}
\hline \multirow[t]{2}{*}{ Variables } & \multicolumn{2}{|c|}{ Self-Efficacy on Condom Use } & \multirow[t]{2}{*}{ COR (95\%) } & \multirow[t]{2}{*}{ AOR (95\%) } \\
\hline & High (\%) & Low (\%) & & \\
\hline \multicolumn{5}{|l|}{ Having life goals } \\
\hline Yes & $200(68.7)$ & $6 \mathrm{I}(48.8)$ & $2.306(\mathrm{I} .50 \mathrm{I}-3.543)^{*}$ & $1.736(1.021-2.951)^{* *}$ \\
\hline No & $91(31.3)$ & $64(5 \mid .2)$ & 1 & I \\
\hline \multicolumn{5}{|c|}{ History of previous condom use } \\
\hline Yes & $249(85.6)$ & $77(61.6)$ & $2.829(2.272-6.012)^{*}$ & $1.698(0.694-4.156)$ \\
\hline No & $48(38.4)$ & $42(14.4)$ & I & I \\
\hline \multicolumn{5}{|c|}{ Rating on the religious importance } \\
\hline Yes & 259(89) & $77(61.6)$ & $2.242(2.082-6.002)^{*}$ & $\mathrm{I} .098(0.48 \mathrm{I}-2.506)$ \\
\hline No & $48(30.4)$ & $32(11)$ & I & I \\
\hline \multicolumn{5}{|l|}{ Sexual experience } \\
\hline Yes & $243(83.5)$ & $73(58.4)$ & $3.072(2.250-5.779) *$ & $2.047(I .|4|-3.675)^{* *}$ \\
\hline No & $52(4 I .6)$ & $48(16.5)$ & I & 1 \\
\hline \multicolumn{5}{|c|}{ Exposure condom advertising } \\
\hline Yes & $242(83.2)$ & $91(72.8)$ & $3.832(1.120-3.04)^{*}$ & $2.168(0.391-1.526)$ \\
\hline No & $34(27.2)$ & $49(16.8)$ & I & I \\
\hline \multicolumn{5}{|c|}{ History of unintended sex } \\
\hline Yes & $255(87.6)$ & $79(63.2)$ & $2.787(2.492-6.827)^{*}$ & $1.619(0.707-3.708)$ \\
\hline No & $44(36.8)$ & $38(12.4)$ & I & 1 \\
\hline \multicolumn{5}{|l|}{ Social support } \\
\hline Yes & $262(90)$ & $86(68.8)$ & $2.265(2.390-7.022)^{*}$ & $2.395(I .50 \mathrm{I}-5.458)^{* *}$ \\
\hline No & $39(31.2)$ & $29(10)$ & I & 1 \\
\hline \multicolumn{5}{|l|}{ Knowledge of condom } \\
\hline Knowledgeable & |44(49.5) & $38(30.4)$ & $2.242(1.437-3.500)^{*}$ & $2.535(1.499-4.282)^{* *}$ \\
\hline Not Knowledgeable & $147(50.5)$ & $87(69.6)$ & 1 & $\mathrm{I}$ \\
\hline
\end{tabular}

Notes: *p-value $<0.2 * *$ p-value $<0.05$ I =reference.

approach that involves creating a positive social environment that gives cues about acceptable behavior. This tactic could be included within an approach that emphasizes observational learning and skill-building. ${ }^{52}$ This might be because individuals who feel less support may choose to practice by themselves and may need to take personal responsibilities for their health and report more competence.

This study found that participants who had sexual experience were more likely to use condoms than those who had no previous experience using condoms. This result is similar to the findings of a study done in Nigeria. ${ }^{36}$ This positive association between sexual experience and condom use is due to the fact that self-efficacy is developed through successful accomplishments in previous experience. Having successfully used condoms in past experience thus contributes to an individual's sense of self-efficacy regarding condom use.

Our findings revealed that study participants who had life goals were significantly associated with self-efficacy on condom use. This result was in agreement with a finding of research conducted on a sample of 7409 sexually active 15-24 years old South African youth. ${ }^{30,53}$ This is supported by the social cognitive model in which long-range goals and opportunities in life contribute to condom using behavior.

\section{Conclusions}

The finding of this study showed that participants who had sexual experience, social support, knowledge of condom, and having life goals were found to be significantly associated with condom use self-efficacy. These results suggest ways to 
increase self-efficacy for condom use among youth that can increase the effectiveness of future interventions for youth.

\section{Abbreviations}

AIDS, acquired immune deficiency syndrome; AOR, adjusted odds ratio; COR, crude odds ratio; HIV, human immune virus; United Nations Aids for International Development; UNEFPA, United Nations Fund for Population Activities; SPSS, Statically Package for Social Science; STI, sexually transmitted infection; WHO, World Health Organization.

\section{Data Sharing Statement}

The data that support the findings of this study are available but some restrictions may apply to the availability of these data as there are some sensitive issues. However, data are available from the corresponding authors upon reasonable request.

\section{Ethical Approval}

Ethical clearance letter was obtained from Wolaita Sodo University, College of Health Sciences; Department of Midwifery institutional review board. Written permission letters were obtained from Sodo town educational office. According to the basic principles of the declaration of Helsinki, participants were informed about the right to self-determination and right to make an informed decision regarding participation in the research, the welfare of the subject taken precedence over the interest of science and society, ethical considerations were taken based on laws and regulations, and also their rights were kept. The participants were told about the objectives of the study and reassured about the confidentiality of the findings. Written consent was obtained from each participant. For those who were at the age of less than 18 written parental consent was also taken from each respondent's parent to participate in the study.

\section{Acknowledgments}

We would like to thank Wolaita Sodo University, College of Health Sciences, and the Department of Midwifery. Our invaluable thanks go to Sodo town educational office for writing letters of permission to each preparatory school. Since this work without them was impossible, we also would like to thank data collectors, supervisors, and study participants.

\section{Author Contributions}

All authors contributed to data analysis, drafting or revising the article, gave final approval of the version to be published, and agree to be accountable for all aspects of the work.

\section{Authors' Information}

- Natnael Atnafu Gebeyehu and Kebreab Paulos Chanko are Lecturers in the Department of Midwifery, College of Health Science and Medicine, Wolaita Sodo University, Wolaita Sodo, Ethiopia

- Yibeltal Mesfin Yesigat is a lecturer in the Department of Midwifery, College of Health Science and Medicine, Woliktie University, Wolkitie, Ethiopia

\section{Funding}

Wolaita Sodo University is the sponsor of this research since it was a scientific paper for partial fulfillment of the bachelor of degree. However, there are not any applicable grant numbers for the funding.

\section{Disclosure}

The authors declare that they have no competing interests.

\section{References}

1. Tarkang EE. Factors Influencing Consistent Condom Use among Secondary School Male Students in Limbe Urban City, Cameroon. Journal of Scientific Research and Reports. 2014;4(2):101-113. https://doi.org/10.9734/JSRR/2015/11334

2. Thanavanh B, Harun-Or-Rashid M, Kasuya H, Sakamoto J. Knowledge, attitudes and practices regarding HIV/AIDS among male high school students in Lao People's Democratic Republic. $J$ Int AIDS Soc. 2013;16(1):17387.

3. UNFPA. Adolescent sexual and reproductive health in 2014. Available from: https://www.unfpa.org/resources/adolescent-sexualand-reproductive health. Accessed July 30, 2020.

4. World Health Organization. Health for the world's adolescents [Multimedia online report] 2014. Available from: http://apps.who. int/adoles cent/second-decade/. Accessed July 30, 2020.

5. World Health Organization. Global Accelerated Action for the Health of Adolescents (AA-HA!): Guidance to Support Country Implementation. Geneva, Switzerland: Author; 2017.

6. UNAIDS \& The African Union. Empower Young Women and Adolescent Girls: Fast-Tracking the End of the AIDS Epidemic in Africa. Geneva: Switzerland Joint United Nations Programme on HIV/AIDS; 2015.

7. UNAIDS: AIDSinfo. 2017. Available from: http://aidsinfo.unaids org. Accessed October 26, 2017.

8. Mesce D, Sines E. Unsafe Abortion: Facts and Figures. Population Reference Bureau: Washington, DC; 2006. Available from : http://www. prb.org/pdf06/UnsafeAbortion2006.pdf. Accessed August 6, 2020.

9. Federal Ministry of Health. National reproductive health strategy. 2006-2015

10. Federal HIV/AIDS Prevention and Control Office. Federal Ministry of Health: HIV Prevention Package: MARPs and Vulnerable Groups. Addis Ababa, Ethiopia: Federal Ministry of Health; 2011. 
11. UNAIDS. UNFPA, WHO, and UNAIDS: position statement on condoms and the prevention of HIV, other sexually transmitted infections and unintended pregnancy. 2015. Available from: http://www. unaids. org/en/resources/press-center/feature stories/2015/july/20150702_con dcon_prevention. Accessed October 26, 2017.

12. Nielson CM, Harris RB, Nyitray AG, Dunne EF, Stone KM, Giuliano AR. Consistent condom use is associated with a lower prevalence of human papillomavirus infection in men. $J$ Infect Dis. 2010;202(3):445-451. doi:10.1086/653708

13. Condoms and HIV prevention: a position statement by UNAIDS, UNFPA, and WHO. 2009. Available from: http://www.unaids.org/ en/resource/presscentre/featurestories/2009/march/20090319 preven tion position/. Accessed July 30, 2020.

14. Roy KP, Mahapatra B, Bhanot A, Kapoor A, Narayanan SS. Psychosocial correlates of HIV-related sexual risk factors among male clients in southern India. Int J Psychol Behav Sci. 2012;2 (6):245-254. doi:10.5923/j.ijpbs.20120206.08

15. Downs JS, Ashcraft AM, Murray PJ, et al. Video intervention to increase perceived self-efficacy for condom use in a randomized controlled trial of female adolescents. J Pediatr Adolesc Gynecol. 2017;31:291-298.e2. doi:10.1016/j.jpag.2017.10.008

16. Goodman ML, Harrell MB, Gitari S, Keiser PH, Raimer-Goodman LA. Self-efficacy mediates the association between partner trust and condom usage among females but not males in a Kenyan cohort of orphan and vulnerable youth. Afr $J$ Reprod Health. 2016;20 (2):94-103. doi:10.29063/ajrh2016/v20i2.10

17. Mehra D, Östergren P-O, Ekman B, Agardh A. Inconsistent condom use among Ugandan university students from a gender perspective: a cross-sectional study. Glob Health Action. 2014;7(1):22942. doi:10.3402/gha.v7.22942

18. Xu Y, Chen X, Yu B, Joseph V, Stanton B. The effects of self-efficacy in bifurcating the relationship of perceived benefit and cost with condom use among adolescents: a cusp catastrophe modeling analysis. J Adolesc. 2017;61:31-39. doi:10.1016/j.adolescence.2017.09.004

19. Zhao R, Wang B, Fang X, Li X, Stanton B. Condom use and self-efficacy among female sex workers with steady partners in China. AIDS Care. 2008;20(7):782-790. doi:10.1080/09540120701694030

20. Bandura A. Self-efficacy: toward a unifying theory of behavioral change. Psychol Rev. 1977;84(2):191. doi:10.1037/0033-295X. 84.2.191

21. Bandura A. Social cognitive theory: an agentic perspective. Annu Rev Psychol. 2001;52(1):1. doi:10.1146/annurev.psych.52.1.1

22. Black DS, Sun P, Rohrbach LA, Sussman S. Decision-making style and gender moderation of the self-efficacy-condom use link among adolescents and young adults: informing targeted STI/HIV prevention programs. Arch Pediatr Adolesc Med. 2011;165:32. doi:10.1001/ archpediatrics.2011.17

23. Closson K, Dietrich JJ, Lachowsky NJ, et al. Gender, sexual self-efficacy and consistent condom use among adolescents living in the HIV hyper-endemic setting of Soweto, South Africa. AIDS Behav. 2018;22(2):671-680. doi:10.1007/s10461-017-1950-z

24. Kwok QM, Chau JP, Holroyd EA. Examining the relationships between condom use self-efficacy and condom use among mainland Chinese sex workers in Hong Kong. J Nurs Sci Vol. 2010;28(2).

25. Boer H, Mashamba MT. Gender power imbalance and differential psychosocial correlates of intended condom use among male and female adolescents from Venda, South Africa. Br J Health Psychol. 2007;12(1):51-63. doi:10.1348/135910706X102104

26. McCall S, Brady C, Keyia C, Boyd K. Condom negotiation efficacy and condom use attitudes as predictors of condom use in African American college students. J AIDS Clin Res. 2016;7(4):000563. doi:10.4172/2155-6113.1000563

27. Zhao J, Song F, Ren S, et al. Predictors of condom use behaviors based on the health belief model (HBM) among female sex workers: a cross-sectional study in Hubei province, China. PLoS One. 2012;7 (11):e49542. doi:10.1371/journal.pone.0049542
28. Crosby RA, DiClemente RJ, Salazar LF, et al. Predictors of consistent condom use among young African American women. AIDS Behav. 2013;17(3):865-871. doi:10.1007/s10461-011-999 8-7

29. Sterk CE, Klein H, Ellefson KW. Perceived condom use self-efficacy among at-risk women. AIDS Behav. 2003;2:175-182. doi:10.1023/ A: 1023950425731

30. Sayles JN, Pettifor A, Wong MD, et al. Factors associated with self-efficacy for condom use and sexual negotiation among South African youth. J Acquir Immune Defic Syndr. 2006;43(2):226-233. doi:10.1097/01.qai.0000230527.17459.5c

31. Patrão AL, McIntyre M. Socio-demographic, marital, and psychosocial factors associated with condom use negotiation self-efficacy among mozambican women at risk for HIV infection. Int $J$ Behav Med. 2017;24(6):846-853. doi:10.1007/s12529-017-9681-0

32. Federal HIV/AIDS Prevention and Control Office Federal Ministry of Health. Report on Progress Towards Implementation of the UN Declaration of Commitment on HIVIAIDS. Addis Ababa Ethiopia: Federal Ministry of Health; 2010.

33. Dingeta T, Oljira L, Assefa N. Patterns of sexual risk behavior among undergraduate university students in Ethiopia: a cross-sectional study. Pan Afr Med J. 2012;12(33). Available from:: http://www.panafricanmed-journal.com/content/article/12/33/fu.

34. Federal democratic republic of Ethiopia Central Statically Agency. Ethiopian Household Consumption-Expenditure Survey Southern Nations Nationalities Region Report; 2018.

35. Shawano and Tekletsadik. Validation of the Condom Use SelfEfficacy Scale in Ethiopia. Vol. 13. BMC International Health and Human Rights; 2013:22

36. Anthony IA 1, Olamijuwon EO. What predicts self-efficacy? Understanding the role of sociodemographic, behavioral, and parental factors on condom use self-efficacy among university students in Nigeria in 2019. PLoS One. 2019. doi:10.1371/journal. pone. 0222701

37. Sayles JN, Pettifor A, Wong MD. Factors associated with selfEfficacy for condom use and sexual negotiation Among South African youth. J Acquir Immune Defic Syndr. 2006;43(2).

38. Carey MP, Schroder KEE. Development and psychometric evaluation of the HIV knowledge questionnaire. AIDS Educ Prev. 2012;14:174-184.

39. Semple SJ, Strathdee SA, Gallardo Cruz M, Robertson A, Goldenberg S, Patterson TL. Psychosexual and social-cognitive correlates of sexual risk behavior among male clients of female sex workers in Tijuana, Mexico 2010. AIDS Care. 2010;22 (12):1473-1480. doi:10.1080/09540121003758648

40. Ali MS, et al. consistent condom use and associated factors among HIV-positive clients on antiretroviral therapy in North West Ethiopian health centers 2016. AIDS Res Treat. 2019. doi:10.1155/2019/ 7134908

41. Alene KA. Consistent Condom Use Among Sexually Active HIVPositive Women in the Amhara Region. Ethiopia: Dove press Open access journal of contraception; 2014.

42. Shewamene Z, Legesse B, Tsega B, Bhagavathula AS, Endale A. Consistent condom use in HIV/AIDS patients receiving antiretroviral therapy in Northwestern Ethiopia: implication to reduce transmission and multiple infections. HIV AIDS (Auckl). 2015;7:119.

43. Ajayi AI, Ismail KO, Akpan W. Factors associated with consistent condom use: a cross-sectional survey of two Nigerian universities in 2019. BMC Public Health. 2019;19(1):1207.

44. Wang L-H, Yan J, Yang G-L, et al. Prevalence of consistent condom use with various types of sex partners and associated factors among money boys in Changsha, China. J Sex Med. 2015;12(4):936-945. doi: $10.1111 /$ jsm. 12821

45. Eggers SM, Aarø LE, Bos AER, et al. Predicting condom use in South Africa: a test of two integrative models 2014. AIDS Behav. 2014;18(1):135-145. doi:10.1007/s10461-013-0423-2 
46. Ibrahim N, Rampal L, Jamil Z, et al. Effectiveness of peer-led education on knowledge, attitude and risk behavior practices related to HIV among students at a Malaysian public University a randomized controlled trial. Prev Med. 2012;55(5):505-510. doi:10.1016/j.ypmed.2012.09.003

47. Shikwane ME, Villar-Loubet OM, Weiss SM, et al. HIV knowledge, disclosure and sexual risk among pregnant women and their partners in rural South Africa. SAHARA-J. 2013;10(2):105-112. doi:10.1080/ 17290376.2013 .870696

48. Volkmann T, Wagner KD, Strathdee SA, et al. Correlates of selfEfficacy for condom use among male clients of female sex workers in Tijuana, Mexico. Arch Sex Behav. 2014;43(4):719-727. doi:10.1007/ s10508-013-0149-2

49. Safarian I. Process assessment of a peer education program for HIV prevention among sex workers in Dahaka, Bangladesh 2012: a social support framework. Soc Sci Med J. 2012;75(4):668-675
50. Peterson CH, Buser TJ, Westburg NG. Effects of familial attachment, social support, involvement, and self-esteem on youth substance use and sexual risk-taking 2010. Fam J. 2010;18(4):369-376. doi:10.1177/1066480710380546

51. Mpondo F, Ruiter RA, et al. Self-determination and gender-power relations as predictors of condom use self-efficacy among South African women. Health Psychol Open. 2015;2(2):205510291559867. doi:10.1177/2055102915598676

52. Yang X, Xia G, Li X, Latkin C, Celentano D. Social influence, and individual risk factors of HIV unsafe sex among female entertainment workers in China in 2010. AIDS Educ Prev. 2010;22(1):69-86. doi:10.1521/aeap.2010.22.1.69

53. Louw J, Peltzer K, Chirinda W, et al. Correlates of HIV risk reduction self-efficacy among youth in South Africa. Sci World J. 2012;2012:1-8. doi:10.1100/2012/817315

HIV/AIDS - Research and Palliative Care

\section{Publish your work in this journal}

HIV/AIDS - Research and Palliative Care is an international, peerreviewed open-access journal focusing on advances in research in HIV, its clinical progression and management options including antiviral treatment, palliative care and public healthcare policies to control viral spread. The manuscript management system is completely online and includes a very quick and fair peer-review system, which is all easy to use. Visit http://www.dovepress.com/testimonials.php to read real quotes from published authors. 